\title{
MODOS
}

\section{Ascensão e declínio da curadoria pedagógica}

Rise and fall of pedagogical curatorship

\section{Dr. Cayo Honorato}

Como citar:

HONORATO, C. Ascensão e declínio da curadoria pedagógica. MODOS. Revista de História da Arte. Campinas, v. 4, n.2, p.27-37, mai. 2020. Disponível em: <https://www.publionline.iar.unicamp. br/index.php/mod/article/view/4328>.

DOI: https://doi.org/10.24978/mod.v4i2.4328.

Imagem: Shibboleth, [2007], Doris Salcedo, Tate Modern Museum, Londres. Fonte: <https://commons. wikimedia.org/>. 


\title{
Ascensão e declínio da curadoria pedagógica
}

\author{
Rise and fall of pedagogical curatorship
}

\section{Dr. Cayo Honorato*}

\begin{abstract}
Resumo
O artigo pretende discutir a trajetória da curadoria pedagógica em duas das principais exposições de arte no Brasil, buscando assim contribuir com a história dessas exposições no país. Nesse percurso, discute-se algumas das condições de emergência dessa atividade, assim como o que ela teria produzido. Também se especula sobre as consequências de sua diluição ou mesmo extinção. Partindo de comentários de Gabriel Pérez-Barreiro, curador da 6a Bienal do Mercosul em 2007 e da 33a Bienal de São Paulo em 2018, dos quais retira tanto um índice de questões quanto algumas categorias de análise, 0 artigo adota uma forma ensaística na qual as histórias dessas duas exposições se cruzam de maneira talvez inesperada. 0 resultado é uma reflexão sobre as questões abertas para a mediação (ou educação) em exposições de arte nessa década (de 2007 a 2017), a partir de sua "promoção" a curadoria. A conclusão é que, se a curadoria pedagógica foi extinta, talvez não seja o caso revivê-la.
\end{abstract}

\section{Palavras-chave}

Bienal de São Paulo. Bienal do Mercosul. Curadoria pedagógica. Curadoria educativa. Mediação cultural.

\begin{abstract}
The article discusses the trajectory of pedagogical curatorship in two of the main art exhibitions in Brazil, thus seeking to contribute to the history of these shows in the country. Furthermore, it calls attention to some of the emergency conditions of this activity, as well as what it has produced. It also speculates about the consequences of the dilution or even the extinction of pedagogical curatorship in art shows and institutions. Based on comments by Gabriel Pérez-Barreiro, curator of the 6th Mercosur Biennial in 2007 and the 33rd São Paulo Biennial in 2018, from which the text draws both an index of questions and some categories of analysis, the analysis adopts an essayistic form in which the stories of these two exhibitions intersect in perhaps unexpected ways. The result is a reflection on the questions open to mediation (or education) in art exhibitions in that decade (from 2007 to 2017), considering its "promotion" to curatorship. As conclusion, it points out that if the pedagogical curatorship has been extinguished, it may not be the case to revive it.
\end{abstract}

\section{Keywords}

São Paulo Biennial. Mercosur Biennial. Pedagogical Curatorship. Educational Curatorship. Cultural Mediation. 
Em 13 de dezembro de 2017, em um encontro organizado pelo Fórum Permanente e pelo Instituto de Estudos Avançados da USP, o então curador da 33a edição da Bienal de São Paulo, Gabriel PérezBarreiro, em resposta às perguntas de llana Goldstein (convidada como debatedora do encontro) e Martin Grossmann (seu organizador) sobre as estratégias de mediação cultural da exposição, afirmou o seguinte:

No momento da Bienal do Mercosul, em 2007, eu achava uma prioridade muito grande colocar o curador pedagógico no centro do projeto. 0 primeiro curador a ser chamado foi, de fato, o [Luis] Camnitzer e sua ideologia permeou toda a estrutura e todo o sistema de mediação [daquela exposição]. Nessa década [2007-17], aconteceu muita coisa na arteeducação no Brasil. Eu acho que a gente contribuiu com alguma coisa, mas também a gente criou um monstro, talvez. (...) Essa ideia de que a instituição tivesse um projeto educativo permanente era uma coisa do Justo [Werlang, então vice-presidente da Fundação Bienal do Mercosul], dessa edição, e a gente participou muito na construção [disso]. A Bienal de São Paulo tem uma história muito específica com essa história de educativo permanente e aí ele se desloca da curadoria [artística ou geral]. Tudo isso que a gente queria, que era uma integração [entre as diferentes curadorias, artística e pedagógica], na verdade ele [sic] criou um divórcio uns anos depois. Chega esse ano [2017] e vem esse assunto; a mediação é fundamental nesse projeto [da 33a Bienal de São Paulo], só que ela não está tão visível. Fazendo uma reflexão sobre essa década, é importante que ela esteja [no projeto], não necessariamente que ela apareça como uma manchete; porque era manchete nessa época [em 2007]. A gente chamou a Lilian [L'Abbate] Kelian e a Helena [Freire] Weffort para fazerem o projeto educativo, que são pessoas, justamente, que não são de arte-educação; são de educação, de educação democrática. A gente queria educadores, um pouco para tirar alguns vícios que a gente identificou sobre arte-educação aqui no Brasil (Fórum Permanente, 2017).

Assim, em poucas palavras e de maneira não necessariamente intencional, o curador tocou em pontos cruciais para um balanço do trabalho da mediação cultural (ou educação) em exposições de arte no Brasil na última década, particularmente em duas das principais exposições de arte do país: a Bienal de São Paulo e a Bienal do Mercosul. Contudo, uma vez que sua resposta não teve naturalmente 0 tempo necessário para ser detalhada, muitas questões restaram pendentes: (1) quais condições, para além de uma decisão curatorial, teriam permitido à curadoria pedagógica ocupar o centro do projeto em 2007 ? (2) que "muita coisa" teria acontecido na arte-educação na última década, particularmente, no âmbito da mediação em exposições? (3) de que forma a $6^{\text {a }}$ Bienal do Mercosul teria contribuído com isso? (4) a que corresponde aquele "monstro" e de que modo ele teria sido criado? (5) que história a Bienal de São Paulo tem com o educativo permanente? (6) de que maneira o desejo de integração entre as curadorias (geral e pedagógica) teria terminado num "divórcio"? (7) de que modo o lugar "menos visível", embora "fundamental", reservado à mediação na 33a Bienal de São Paulo deriva de uma reflexão sobre essa década? (8) quais "vícios" teriam sido identificados sobre a arte-educação no Brasil?

O conjunto dessas questões, certamente, envolve a consideração de muitos aspectos dessa história, que excedem a capacidade deste artigo. No entanto, parece-me oportuno considerar - mesmo que de maneira não exaustiva - a trajetória da curadoria pedagógica nesse período. Ainda que aquelas duas exposições dificilmente representem o que se passa no campo da mediação cultural em todo o país, são elas que projetam o uso do termo em questão no Brasil. Além disso, é a curadoria pedagógica (em sua intimidade com a ideia de um educativo permanente) que nos permitirá ponderar sobre o lugar reservado à mediação num certo "organograma" das exposições, assim como sobre o lugar reservado aos públicos (e suas demandas) dentre os compromissos das instituições de arte. Considerá-la a partir do comentário de Pérez-Barreiro tem ainda a vantagem de estabelecer uma periodização conclusiva: embora o declínio do termo (ou, mais do que isso, do seu campo de ação) já estivesse em processo 
desde 2014 - com a saída de Stela Barbieri da curadoria pedagógica da Bienal de São Paulo -, ninguém estaria mais autorizado do que Pérez-Barreiro, naquele momento, para interromper as expectativas de que aquela função fosse reabilitada. Sua posição adquire então uma especial duplicidade: se em 2007, como curador da Bienal do Mercosul, ele esteve à frente da institucionalização da curadoria pedagógica, em 2017-18, como curador da Bienal de São Paulo, ele sugere que o "monstro" ou mesmo o "divórcio" (entre as diferentes curadorias) devem ser evitados.

Mais do que isso, talvez pudéssemos admitir, a partir desse momento, que a própria função da curadoria pedagógica - no sentido de uma prática tão importante quanto a curadoria artística - tenha sido extinta, e que seus usos atuais - como o que se praticou na $2^{\mathrm{a}}$ edição da Trienal Frestas (2017), por exemplo - não passam de usos nominais, isto é, que não necessariamente consideram os componentes que davam ao conceito sua consistência própria. Sendo assim, também me parece oportuno discutir o que ela pôde produzir, bem como especular sobre as consequências de sua extinção. De um modo geral, sua invenção em 2007 passa pelo entendimento de que (1) tanto a exposição quanto os públicos possuem a mesma importância, ou ainda de que (2) a recepção é também uma instância de produção de significados e experiências, e que (3) os programas educativos, portanto, deveriam ser concebidos simultaneamente às exposições, ou mesmo para além delas, em vez de lhes serem acrescentados a posteriori, como uma simples ferramenta de extensão dos seus conteúdos, quando não de convencimento dos públicos a respeito de sua qualidade postulada. A partir desse entendimento, houve uma ampliação do espaço de atuação da mediação, emblematizada no conceito de curadoria pedagógica. Certamente, isso questiona uma visão curatorial típica, que se contenta em selecionar e distribuir obras no espaço, propondo além disso um envolvimento com o que surge no tempo da exposição, a partir das interações que ocorrem nessa duração, de maneira muitas vezes inesperada. Nessa duração, que em geral só existe para a curadoria artística como programação, as oportunidades de debate e aprendizagem são abundantes, além de cada vez mais conflitivas.

De fato, muito rapidamente, isso transforma tanto as premissas quanto a própria organização daquelas instituições. Em Porto Alegre, a Bienal teria se tornado pedagógica: "uma bienal que professa concentrar-se na função educativa da arte por cima da ideia de um campeonato mercantil", ou ainda, "um instrumento radicalmente dedicado à transformação cultural" (Camnitzer, 2009: 13). Conforme a proposta de Luis Camnitzer, "a Bienal se auto-define como uma instituição de ação cultural de caráter permanente, dentro da qual a exposição periódica é somente uma das atividades" (apud Hoff, 2013: 73). Em São Paulo, para onde o modelo aparentemente foi exportado, a instituição da curadoria pedagógica em 2009/2010 é sucedida pela implementação de um Educativo Permanente no ano seguinte, embora dessa vez seu projeto e conceituação não fossem muito claros. Na ocasião, Stela Barbieri (2011) se limita a declarar que a presidência e a diretoria, "cientes da importância dos serviços educativos das bienais anteriores e de seu trabalho significativo", haviam decidido consolidar um Educativo Permanente, "responsável pela relação direta da Bienal com o público". Conforme o Relatório de Gestão 2011-12 da Fundação Bienal, o propósito dessa iniciativa é "poder oferecer uma formação continuada, ampliar o diálogo com professores, fortalecer redes e inserir as ações do Educativo Bienal no calendário escolar" (Fundação Bienal de São Paulo, 2012).

Mas são casos certamente muito distintos. Ao contrário de Barbieri, que atuou como curadora pedagógica em três diferentes edições da exposição (2010, 2012 e 2014), além de responsável pelas inúmeras ações do Educativo Permanente entre uma edição e outra, Camnitzer não se tornou um "curador permanente". As edições seguintes da Bienal do Mercosul tiveram cada qual um novo curador pedagógico, que podia contar com o apoio de uma coordenação local, cuja atuação - essa sim atravessou diferentes edições. Mônica Hoff, que exerceu essa função até finalmente tornar-se curadora 
pedagógica em 2013, ao considerar as relações entre as curadorias, afirmou que "as negociações entre as curadorias artística e educativa [em Porto Alegre] foram sempre amigáveis e profícuas" (Hoff, 2013: 83). Convém esclarecer, no entanto, que os curadores pedagógicos aí sempre foram convidados pela curadoria artística e que, portanto, alguma afinidade entre as duas instâncias podia ser pressuposta. Já em São Paulo, a curadoria pedagógica esteve nas mãos de uma única curadora, com a qual todas as novas curadorias artísticas tiveram de se relacionar - o que teria finalmente produzido (em 2014) 0 "divórcio" a que Pérez-Barreiro se referiu. Considerando ainda a perspectiva de Hoff, os projetos resultantes daquelas negociações amigáveis chegaram a uma "integração total" em 2011, quando 0 curador pedagógico - posição então ocupada por Pablo Helguera - também passou a atuar na concepção de estratégias expositivas e seleção dos artistas participantes. Neste ponto, podemos inclusive observar mudanças "internas" ao conceito, se compararmos essa "integração" com a proposta inicial de Camnitzer, para quem o curador pedagógico é "(...) alguém que não influi na seleção dos artistas. É alguém que atua como um embaixador do público e observa o evento com os olhos do visitante" (Camnitzer, 2009: 15).

Mas o que significa ser um embaixador do público, ou ainda, observar a exposição com os olhos do visitante? Camnitzer (2009: 18) ressalva que "nunca poderemos assumir completamente os olhos do público", mas que, ao menos, podemos "aproximar-nos o máximo possível da perspectiva do visitante sem cair em demagogias paternalistas". Considerando particularmente 0 caso dos públicos que não têm experiência com exposições de arte, Camnitzer entende haver discrepâncias entre a perspectiva do visitante e o código de leitura "bastante complexo" das exposições. Assim, propõe que esse código - segundo ele, "o primeiro passo verdadeiro de acesso à arte" - seja aquilo que se deve aprender, mais do que informações anedóticas sobre obras e artistas. Embora atento ao que poderiam ser alguns "vícios" da arte-educação (ou daqueles que, não sendo educadores, projetam suas funções), por exemplo, os que reduzem a mediação à simples oferta de informações ${ }^{1}$, seu conceito de curadoria pedagógica denota neste ponto certa unidirecionalidade: são os visitantes que devem aprender tal código. Noutros termos, ele não considera que as exposições também pudessem se aproximar da "perspectiva do visitante", que não necessariamente diz respeito à arte, deslocando-se à ponderação de outras questões presentes na esfera pública. Também ele não considera que o papel das instituições talvez não seja o de sempre iniciar processos de aprendizagem (em arte), podendo eventualmente demonstrar que aprendem e se transformam a partir daquela perspectiva, tendo em conta suas dimensões sociais, políticas e/ou culturais.

Em todo caso, segundo Camnitzer (2009: 15), o conceito de curadoria pedagógica "partiu de uma decisão de Gabriel Pérez-Barreiro quando encomendaram a ele a curadoria geral da Bienal [do Mercosul]". Todavia, convém registrar que uma das primeiras ocorrências do termo no Brasil aparecera dez anos antes, em um artigo de Luiz Guilherme Vergara. Em observação que parece destinada aos curadores, Vergara (1996) defende que "tornar [sic] arte acessível a um público diversificado é torná-la ativa culturalmente". Trata-se com isso de expandir o conceito de curadoria, mediante a incorporação de preocupações educativas, e não de promover a educação a curadoria, como ocorreu entre 2007 e 2011. Certamente, Vergara não contava com o mesmo contexto. De qualquer forma, são caminhos diferentes em busca de um objetivo comum, qual seja, a ampliação de certa presença (transformadora) da educação nas exposições (e instituições) de arte. Porém, enquanto a primeira ocorrência buscava convencer a curadoria artística da importância da educação e dos públicos, a segunda estabeleceu como premissa a existência de duas curadorias - o que deu lugar tanto a uma relação mais igualitária, de colaboração entre educativo e curadoria, quanto a uma partilha conflitiva de territórios, poderes e visibilidades. 
Outro aspecto a ser considerado diz respeito, como dissemos, à relação da curadoria pedagógica com um processo de reorganização da instituição, que resultou, em ambos os casos na implementação de um "educativo permanente". Posto isso, se a ideia de que a Bienal do Mercosul tivesse um educativo permanente foi, segundo Pérez-Barreiro, "uma coisa do Justo [Werlang]", convém registrar que a implementação do Educativo Permanente na Bienal de São Paulo concretizou uma vontade antiga da instituição, "para a qual iniciativas não faltaram" (Minerini Neto, 2014: 386). Em sua tese sobre a história da educação na Bienal paulistana, José Minerini Neto enumera uma quantidade de propostas de cursos, centros, setores e diretorias, que pretenderam assegurar à educação um lugar permanente na instituição. De forma mais explícita, porém, a recomendação irá aparecer no relatório da curadoria da $28^{a}$ Bienal (2008), intitulada Em Vivo Contato, concluído em abril de 2009, no qual Ana Paula Cohen e Ivo Mesquita afirmam que "a falta de continuidade nos programas e atividades da Fundação é o seu ponto mais fraco e vulnerável, com um alto custo financeiro", combinada à ideia de que "um serviço educativo permanente seria um espaço de reserva de conhecimento e acúmulo de experiência", a partir do qual se poderia "desenvolver um programa mais efetivo e sistemático junto aos diversos públicos que frequentam a Bienal” (Cohen; Mesquita, 2009).

Essa recomendação, no entanto, coincide com outros eventos. Muito antes de Pérez-Barreiro, Werlang já tinha efetuado um cruzamento entre os caminhos das duas Bienais. Nesse mesmo ano, o empresário passou a integrar a diretoria da Bienal paulistana, então sob a presidência de Heitor Martins. $O$ jornal Folha de São Paulo de 13 de julho de 2009 noticia que a Bienal havia importado o modelo gaúcho de gestão (Folha de São Paulo, 2009). Segundo a matéria, em menos de dez anos de existência, a Bienal do Mercosul havia alcançado um público comparável ao de sua congênere paulistana, custando, porém, um terço menos. Na ocasião, Werlang teria dito que a manutenção de uma estrutura fixa, incluindo 0 projeto pedagógico, era parte do sucesso. Sua posição, somada à recomendação de Cohen e Mesquita, terá sido decisiva à implementação do Educativo Permanente na Bienal de São Paulo, ao qual a ideia da curadoria pedagógica está intimamente vinculada. Na verdade, desde 2006, desenhava-se um contexto favorável para tanto, em âmbito internacional, a partir da chamada "virada educacional" (O'Neill; Wilson, 2010), cujo caso paradigmático é a Manifesta 6, que propunha uma escola em vez de uma exposição de arte. No Reino Unido, por exemplo, enquanto o investimento nos programas educativos crescia, ele diminuía na aquisição de obras de arte (Morton, 2006). Além disso, ao menos no Brasil, a educação se apresentava como uma justificativa incontestável para o financiamento público das exposições de arte, que, no mais das vezes, enfrentam a desconfiança do público em geral quanto à sua utilidade social. Em todo caso, a Bienal do Mercosul teve sua astúcia ao perceber que essa plataforma poderia destacá-la, como de fato o fez, no panorama das bienais internacionais.

Mas por que essa plataforma teria entrado em declínio? Em São Paulo, Stela Barbieri não teve sucessor. Com sua saída, o Programa Educativo passou à responsabilidade de uma coordenação, gerência ou consultoria. A instituição pode alegar que o educativo permanece depois disso, mas não com o mesmo vulto. Na 32a Bienal (2016), intitulada Incerteza Viva, realizada sob a curadoria de Jochen Volz, o educativo foi fragmentado em diferentes ações (mediação, difusão e material educativo), encomendadas cada uma a diferentes profissionais. Sua importância foi claramente diluída. Em Porto Alegre, na 10a Bienal (2015), intitulada Mensagem de uma nova América, sob a curadoria geral de Gaudêncio Fidélis, a curadoria pedagógica foi substituída pelo esdrúxulo posto de "dialogante", em posição deliberadamente subsidiária. A crise financeira enfrentada desde então pela instituição, com base na sua própria experiência, não justifica a mudança (conceitual e política) de plataforma. Embora de fato muita coisa tenha acontecido para a mediação nessa década, não há mais sinal da inversão proposta por Camnitzer, ao conceber a exposição como atividade periódica de uma instituição permanentemente educativa. Em entrevista de 2007, o então curador antecipara que "com o passar do 
tempo talvez a deterioração seja inevitável e então se terá de desenvolver um novo modelo" (Camnitzer; Honorato, 2008: 80, tradução minha). Mas certamente haverá causas para essa deterioração, ainda que multifatoriais e nem sempre (publicamente) acessíveis. Em todo caso, o "monstro" e o "divórcio" me parecem metáforas bastante oportunas para se pensar o que houve.

Minha hipótese é que dois fatores, um para cada caso, foram decisivos para a extinção da curadoria pedagógica. No caso de Porto Alegre, terá prestado um papel considerável a sublevação dos mediadores em 2013. Como se sabe, no último dia da 9a Bienal do Mercosul (2013), intitulada Se o clima for favorável, parte dos mediadores realizou uma "paralis(AÇÃO)", em protesto contra as práticas institucionais que, segundo eles, restringiam de forma discriminatória o acesso dos públicos. Segundo o Coletivo Autônomo de Mediadorxs formado na ocasião, a realização de um jantar de arrecadação semanas antes, nas dependências do Museu de Arte do Rio Grande do Sul - que sediava parte da exposição -, não só dificultou o acesso dos visitantes em horário de visitação, como contrariou normas de segurança e preservação das obras. Determinadas pela própria instituição, essas normas deveriam ser observadas tanto pelos visitantes quanto pelos mediadores. Apesar disso, o jantar fora realizado dentro do próprio espaço expositivo, ao lado de obras de arte em exibição (Coletivo Autônomo de Mediadorxs, 2013). Na época, o Museu era dirigido por Gaudêncio Fidélis, tendo o jantar sido uma iniciativa sua. Certamente, a "paralis(AÇÃO)" não foi uma consequência do trabalho da curadoria pedagógica, embora a existência dessa curadoria conferisse à mediação mais autonomia. De qualquer forma, a escolha de Fidélis como curador geral da Bienal seguinte, em 2015, nos aponta que lado da controvérsia a instituição decidiu avalizar.

No caso de São Paulo, um fator decisivo terá sido as divergências manifestadas entre as duas curadorias (geral e pedagógica) na 31ª Bienal (2014), intitulada Como (...) Coisas Que Não Existem. Embora não tenham sido documentadas, tais divergências se tornaram notórias nos meses de preparação da exposição, conforme relatos de diferentes atores envolvidos². A propósito, apesar de Barbieri haver alegado motivos pessoais ${ }^{3}$, seu desligamento em data próxima à abertura da exposição parece indicar, para além de uma temporalidade própria da "permanência", tanto a sua exaustão pessoal quanto a deste conceito. Em todo caso, a ideia de "divórcio" denota uma leitura particular: ela pressupõe uma relação de casamento estabelecida entre as curadorias - 0 que pode ser estruturalmente válido para Porto Alegre, mas não para São Paulo, pelos motivos que apresentei acima. Também ela nos deixa pensar nas consequências dessa "separação", para cada uma das partes, nos termos de uma "partilha de bens", por assim dizer. Por exemplo, quanto à distribuição de poderes e visibilidades entre as diferentes curadorias, o episódio não rendeu à curadoria pedagógica nenhuma manchete ${ }^{4}$. Sua extinção é, portanto, silenciosa.

Já o "monstro" poderia ter duas acepções. No caso de Porto Alegre - embora não exclusivamente -, são os "excessos de democracia" que devem ser evitados. A possibilidade sempre tão iminente de um levante por parte dos mediadores, que experimentam a criticidade da arte em meio a condições de trabalho precárias e subalternizadas, amedronta as instituições. Tal possibilidade é certamente potencializada pelo sentimento de importância da educação nas exposições, o que, da perspectiva em questão deve ser controlado. Helguera, por exemplo, reconheceu em 2011 haver "uma disposição única para o campo da mediação na cidade de Porto Alegre" (Helguera, 2011: 5). Mas aqui é preciso fazer uma ressalva: se por um lado, a institucionalização da curadoria pedagógica produziu certa redistribuição de poderes internamente às instituições, por outro, ela ampliou a hierarquia interna dos educativos. A posição do curador não deveria ser confundida com a dos coordenadores, nem com a dos supervisores, muito menos com a dos mediadores. Na $31^{\text {a }}$ Bienal de São Paulo, por exemplo, a curadoria pedagógica teria se preocupado com a possibilidade de os mediadores se aliarem aos 
artistas, voltando-se contra o Educativo e a instituição (Honorato, 2019). Além disso, nas equipes reduzidas que permanecem em ambas as instituições, os mediadores não costumam ser permanentes.

No caso de São Paulo, o "monstro" parece ter assumido a forma de um doppelgänger. O Educativo Permanente terminou construindo uma instituição paralela, com sua própria equipe de produção, comunicação, relações externas e internas, além de seus próprios patrocinadores - como talvez não pudesse ser de outra forma, dadas a escala e especificidade do trabalho. Mas é possível que, em algum momento, a instituição duplicada tenha receado ser substituída, o que a teria feito dar cabo de seu duplo. O problema, de fato, é que o Educativo Permanente da Bienal se desenvolveu sem um projeto muito claro de mediação, de forma algo personalista, sob a condução de uma única curadora. Conceitualmente, esse Educativo se sustentava em três eixos curatoriais: diálogo, experiência e encontro, que na prática funcionavam como uma espécie de dispositivo, responsável pela produção de certa conciliação entre permanência e permeabilidade, considerando-se neste caso as questões trazidas por cada nova curadoria geral, em relação às quais o próprio Educativo deveria demonstrar sua disponibilidade para aprender. Em última análise, eles sinalizavam uma abertura (discursiva) às mudanças, em meio a um compromisso (pragmático) com a sua própria reprodução.

Assim, cabe observar que, quando Pérez-Barreiro diz "a gente criou um monstro", é como se o monstro fosse uma consequência direta do projeto de 2007 - o que dificilmente é verdadeiro, apesar da já referida "importação" do modelo gaúcho por São Paulo. Do mesmo modo, quando ele diz que "ele [não ficou claro exatamente quem] criou um divórcio", se consideramos as diferenças de visibilidades entre as distintas curadorias, é como se a subordinação de uma à outra fosse natural - 0 que pode ser questionado. Mais propriamente, o curador parece assumir a percepção da instituição Bienal de São Paulo - possivelmente informada por um risk management - a respeito do que tinha havido naquele contexto. Em todo caso, se por um lado Pérez-Barreiro resolve "radicalizar" alguma coisa do experimento curatorial de 2007, transformando a mostra Conversas - na qual os artistas já atuavam como curadores - no próprio "sistema operacional" da 33a Bienal, intitulada Afinidades Afetivas atestando com isso certa continuação entre as duas exposições -, por outro, retomar a curadoria pedagógica não foi sua prioridade. Desta vez, o curador declara apostar em uma "educação do olhar", a partir do sistema de relações organizado pelo pensamento dos artistas. Noutros termos, ele declara confiar que as relações entre os trabalhos, a partir da pergunta sobre como funcionam juntos, seriam legíveis por si só, dispensando explicações ou leituras contextualizadas (Fórum Permanente, 2017).

Por certo, "explicar" não seria o trabalho da mediação, mas ainda denota o que muitos curadores e visitantes esperam desse trabalho. A propósito, mesmo em Porto Alegre, pode ser que a integração entre as curadorias nunca tenha sido exclusivamente amigável. Convém, neste ponto, retomar o que Camnitzer (2009: 19) afirmou anteriormente: "Dar por certo que esse código [de leitura das exposições] é óbvio e compartilhado é um ato classista e arrogante". Porém, se mesmo a proposta de se ensinar tal código incorre em unidirecionalidade, pressupor sua leitura por parte do visitante - com base em uma narrativa (moderna) centrada na experiência da arte - parece ignorar em boa medida a constituição da arte como um processo social, assim como as condições contemporâneas de atuação dos públicos, para os quais a relação com o campo expandido, interconectado e pós-disciplinar das culturas audiovisuais e digitais - que vai se tornando, especialmente para os jovens, um modus vivendi - não redunda em uma simples falta de atenção5. Nesse sentido, se Pérez-Barreiro propõe "deslocar os lugares de fala e decisão [da curadoria]" (Fundação Bienal de São Paulo, 2017) ao compartilhá-los com os artistas, é para melhor reinstalar a autoridade cultural da arte, em detrimento das culturas mais distribuídas, das quais os públicos em geral são plenos praticantes. Enfim, a curadoria artística também tem seus vícios. 
De resto, pode parecer que se trata aqui de reivindicar um lugar para a curadoria pedagógica. Mas se ela foi extinta, não penso que seria o caso necessariamente revivê-la. O reconhecimento da mediação contido no termo é problemático em si mesmo, por pelo menos duas razões. Em primeiro lugar, por que a mediação, para ser reconhecida, deveria ser "promovida" a curadoria? O próprio termo parece reinscrever uma subordinação do educativo à curadoria. Além disso, parece-me salutar considerarmos as especificidades de cada uma dessas atividades, ou ainda, o espaço próprio de atuação e pesquisa da mediação; assim como elaborarmos os termos de uma efetiva colaboração entre essas atividades algo ainda muito pouco discutido. De fato, não há que se insistir numa disputa, mas a manutenção daquela subordinação tende a limitar a produção de conhecimentos por parte da mediação. Em segundo lugar, considerando a transformação da instituição cultural em instituição pedagógica, essa "promoção" pode redundar numa diluição da mediação na instituição, quando na verdade a mediação poderia - de modo mais decisivamente público - atuar de maneira extrainstitucional, isto é, sem necessariamente reproduzir as demandas tipicamente autorreferentes da instituição.

Apesar dessas ressalvas, a extinção da curadoria pedagógica termina por secundarizar o espaço da mediação nessas instituições - 0 que pode ter as suas consequências. Considerando as guerras culturais em que estamos imersos, a partir do caso Queermuseu e congêneres ${ }^{6}$, e que neste momento são reforçadas pelas políticas do governo Bolsonaro, aquele espaço se torna ainda mais necessário. Por certo, a fragilidade das instituições culturais no Brasil também deve ser considerada, mas é injustificável que os conflitos e crises lhes sirvam de pretexto para reformas conservadoras. Infelizmente, é pelo que muitas instituições têm optado, buscando reafirmar sua hegemonia perdida, em meio às dinâmicas culturais que as têm desafiado de modo cada vez mais incontornável.

\section{Referências}

BARBIERI, S. Apresentação: Mapeando pensamentos. São Paulo: Fundação Bienal de São Paulo, 2011. (Material educativo da exposição Em Nome dos Artistas).

CAMNITZER, L. Introdução. In: CAMNITZER, L.; PÉREZ-BARREIRO, G. (org.). Educação para a arte/Arte para a educação. Porto Alegre: Fundação Bienal do Mercosul, 2009, p. 13-28.

CAMNITZER, L.; HONORATO, C. Arte como atitude. Revista Concinnitas, Rio de Janeiro, v. 1, n. 12 (9), p. 76-85, 2008. Disponivel em: <http://bit.ly/2nFaeLY>. Acesso em: 1 out. 2019.

COHEN, A. P.; MESQUITA, I. Relatório da curadoria da $28^{\mathrm{a}}$ Bienal de São Paulo. Fórum Permanente, São Paulo, abr. 2009. Não paginado. Disponível em: <http://www.forumpermanente.org/event_pres/ exposicoes/28a-bienal/relatorio>. Acesso em: 1 out. 2019.

COLETIVO AUTÔNOMO DE MEDIADORXS. Declaração. Porto Alegre: [s.n.], 05 nov. 2013. Não paginado. Disponível em:
$<$ https://coletivoam.wordpress.com/2013/11/06/
declaracao-2/ >. Acesso em: 1 out. 2019.

DEWDNEY, Andrew; WALSH, Victoria. Da diversidade cultural aos limites do modernismo estético: políticas culturais da coleção nacional, mecanismos de exibição e exposição. Periódico Permanente, São Paulo, n. 6, 2016. Não paginado. Disponivel em: <http://www.forumpermanente.org/revista/nume ro-6-1/sumario>. Acesso em: 1 out. 2019.

FOLHA DE SÃO PAULO. Bienal de São Paulo importa modelo gaúcho de gestão. Folha de São Paulo, São Paulo, 13 jul. 2009. Não paginado. Disponível em: <https://www1.folha.uol.com.br/fsp/ilustrad/fq13 07200908.htm>. Acesso em: 1 out. 2019.

FÓRUM PERMANENTE. Encontro com Gabriel Pérez-Barreiro. Fórum Permanente, São Paulo, 13 dez. 2017. Disponivel em: $<\mathrm{http}: / / w w w . f o r u m p e r m a n e n t e . o r g / e v e n t \_p r e s /$ encontros/encontro-com-gabriel-perezbarreiro/encontro-com-gabriel-perez-barreiro>. Acesso em: 1 out. 2019. 
FUNDAÇÃO BIENAL DE SÃO PAULO. Relatório de gestão e contribuições à sociedade, 2011-2012. São Paulo: Fundação Bienal de São Paulo, 2012. Disponível em: $<$ https://issuu.com/bienal/docs/relatorio_gestao _2011_2012>. Acesso em: 1 out. 2019.

33a Bienal revê o papel da curadoria. Fundação Bienal de São Paulo, São Paulo, 31 out. 2017. Disponivel em <http://www.bienal.org.br/post/4382>. Acesso em: 1 out. 2019.

Convite à atenção. Fundação Bienal de São Paulo, São Paulo, 21 mar. 2018. Disponível em: < http://www.bienal.org.br/agenda/4956 >. Acesso em: 01 out. 2019.

HELGUERA, Pablo. Introdução: In: HELGUERA, Pablo; HOFF, Mônica. Pedagogia no campo expandido. Porto Alegre: Fundação Bienal do Mercosul, 2011, p. 5-7.

HOFF, Mônica. Mediação (da arte) e curadoria (educativa) na Bienal do Mercosul, ou a arte onde ela "aparentemente" não está. Trama Interdisciplinar, São Paulo, v. 4, n. 1, p. 69-87, 2013. Disponivel em: $<$ http://editorarevistas.mackenzie.br/index.php/t int/article/view/5543>. Acesso em: 1 out. 2019.

HONORATO, Cayo. Perishable notes about problems that do not exist: an analysis based on the 31st São Paulo Biennial Educational Program. s.l.: s.n., 2019. Disponível em: <http://www.saopaulobienalstories.org/>.

Acesso em 1 out. 2019.
MINERINI NETO, José. Educação nas Bienais de Arte de São Paulo: dos cursos do MAM ao Educativo Permanente. 2014. Tese (Doutorado em Artes) - ECA USP, São Paulo, 2014. Disponível em: $<$ https://teses.usp.br/teses/disponiveis/27/2716 0/tde-01122014-161256/pt-br.php>. Acesso em: 1 out. 2019.

MOLINA, Camila. "Medidas da Incerteza" é o tema da $32^{\mathrm{a}}$ Bienal de São Paulo, em 2016. 0 Estado de São Paulo, São Paulo, 4 fev. 2015. Não paginado. Disponível em: $<$ https://cultura.estadao.com.br/noticias/artes,m edidas-da-incerteza-e-o-tema-da-32-bienal-desao-paulo-em-2016,1629448 >. Acesso em: 1 out. 2019.

MORTON, Tom. Are you being served? Frieze, London, n. 101, p. 181-183, 2006.

O'NEILL, Paul; WILSON, Mick (ed.). Curating and the educational turn. Amsterdam: Open Editions, 2010.

VERGARA, Luiz Guilherme. Curadoria Educativa: Percepção Imaginativa/ Consciência do Olhar. In: Anais do $8^{\circ}$ Encontro Nacional da ANPAP. São Paulo: ECA USP, 1996. (Republicado em: CERVETTO, Renata; LÓPEZ, Miguel A. (ed.). Agite antes de usar: deslocamentos educativos, sociais e artísticos na América Latina. São Paulo: Edições Sesc São Paulo, 2018, p. 39-46).

\section{Notas}

\footnotetext{
"Professor Adjunto do Departamento de Artes Visuais da Universidade de Brasília (UnB). E-mail: <cayohonorato@unb.br>. ORCID: $<$ <ttp://orcid.org/0000-0002-5220-0691>.

${ }^{1}$ Faço alusão à fala de Gabriel Pérez-Barreiro, mas de fato não é possível deduzir, a partir dela, quais "vícios" ele teria identificado.

${ }^{2}$ Em 2015, entrevistei dez diferentes atores envolvidos na exposição, entre educadores, supervisores, professores, curadores e artistas, para a escrita de um texto sobre o educativo da $31^{\mathrm{a}}$ Bienal de São Paulo, no qual as divergências entre as duas curadorias foi um dos problemas abordados (Honorato, 2019).

${ }^{3}$ Segundo Luis Terepins, então presidente da Fundação Bienal de São Paulo, "o recente desligamento de Stela Barbieri da coordenação do educativo da Bienal (desde a 29a Bienal) foi uma escolha da própria artista e educadora" (Terepins apud Molina, 2015).

${ }^{4}$ De fato, nas mais de 800 páginas do clipping nacional da $31^{\text {a }}$ Bienal, disponibilizado no Arquivo Wanda Svevo da Bienal de São Paulo, não há manchete que mencione o desligamento de Barbieri - o que nos leva a pensar que a "permanência" do educativo sempre foi algo provisório.

${ }^{5}$ Parte das estratégias educativas da exposição, a publicação Convite à Atenção "(...) propõe exercícios que convidam as pessoas a estarem atentas para a experiência com a arte, desde o encontro com a obra até o compartilhamento da reflexão sobre ela" (Fundação Bienal de São Paulo, 2018). A respeito das divergências entre essa expectativa moderna de compreensão da arte e a atuação contemporânea dos públicos, cf. Dewdney; Walsh, 2016.

${ }^{6} \mathrm{Em} 10$ de setembro de 2017, após manifestações de repúdio terem se avolumado pelas redes sociais nos dias anteriores, o Santander Cultural decidiu encerrar a exposição Queermuseu - Cartografias da Diferença na Arte Brasileira, em cartaz na instituição desde o dia 15 de agosto, antecipando seu término em quase um mês. As principais queixas eram de que a exposição - mais precisamente, três
} 
ou quatro obras expostas - fazia apologia à pedofilia e zoofilia, além de blasfemar contra símbolos e valores religiosos cristãos. 0 episódio foi sucedido por uma série de outros eventos, em diferentes cidades brasileiras (Campo Grande, Jundiaí, São Paulo, Belo Horizonte, Fortaleza, Vitória, Brasília), chegando à condução coercitiva do curador da exposição para audiência no Congresso Nacional em 08 de novembro, mediante requerimento aprovado pela chamada CPI dos Maus-tratos.

Artigo recebido em outubro de 2019. Aprovado em março de 2020. 